\title{
Business Process Optimization of the Customer Manager Based on Mobile Internet
}

\author{
Keliang Jia * \\ School of Management Science and Engineering \\ Shandong University of Finance and Economics \\ Jinan, China \\ e-mail: jiakeliang@sina.com \\ Peijiang Liu \\ Shandong Tobacco Research Institute \\ Jinan, China \\ e-mail: 165610804@qq.com
}

\author{
Nan Song \\ Shandong Tobacco Research Institute \\ Jinan, China
}

\begin{abstract}
This paper analyzes the traditional business process of customer manager in tobacco industry and finds out the redundant process and existing problems in the traditional process. In order to provide better and timelier service to the retail customers, the paper optimizes the traditional business process of the customer manager based on mobile Internet technology, eliminates or merges the redundant business process, improves the efficiency of customer manager. Practices show that the optimized business process can improve the efficiency of customer manager and provide better service to the customer.
\end{abstract}

Keywords-business process optimization; customer manager; mobile Internet; tobacco industry

\section{INTRODUCTION}

Business process optimization is a systematic project, improvement and optimization of business processes can maintain the enterprise's competitive advantage. The business process should be continuously improved in order to achieve the best results [1]. The goal of business process optimization is to increase the service time and efficiency of the value-added service, shorten or remove the service time of non value-added service. Business process optimization cannot be separated from the support of information technology; information technology is the tool to provide information integration, information sharing and implementation of business processes, it could improve the operation efficiency of the process. Li Chuanbo et al. [2] optimized the postal logistics business process based on RFID technology. Wang Yunqing [3] researched on the business process optimization of University Library in the information environment. Chu Yuelong[4] studied the optimization principle of enterprise business process based on information technology. Zhang Jian et al. [5] studied the optimization of business process of $\mathrm{B} 2 \mathrm{C}$ e-commerce based on Internet of things. Zhao $\mathrm{Xi}$ [6] proposed an optimization method of business process based on cloud computing architecture. Mobile Internet technology represents the direction of the development of information technology; it is changing the way of live and work. The change of tourism supply chain in the mobile Internet environment was studied by Huang Meng [7]. Zhao Hui [8] studied the cigarette marketing innovation based on mobile Internet technology. Jia Yanbo [9] designed and implemented the tobacco monopoly management and supervision system based on mobile Internet technology. Lv Feng[10] studied the integration and application of tobacco monopolization management system based on mobile internet.

Based on the previous studies, this paper researches the optimization and the improvement of customer manager's business process based on mobile Internet environment.

\section{BUSINESS PROCESS ANALYSIS OF CUSTOMER MANAGER IN TOBACCO INDUSTRY}

Account manager is a bridge between the tobacco companies and the retail customers. In the process of cigarette marketing, customer manager is responsible for the policy propaganda of the tobacco companies and product introduction to the retail customers. He should provide the services to the retail customers as the representative of the company in order to promote sales, and he also should collect some feedback information from the customers. With the continuous development of the tobacco industry, the role and position of the customer manager in the cigarette market is more prominent. How to make full use of the job function of the customer manager in the orientation of the cigarette consumption, cigarette brand market cultivation, market information collection and feedback, sales dynamic analysis, customer running instruction, maintenance and development of customer relationship, industry policy propaganda, effective information transmission and so on, is a very important significance for the better development of the whole cigarette market. Customer manager's work can be divided into outdoor and indoor work according to the work place. Outdoor work is mainly to visit the retail customers and to provide quality services for them; indoor work is mainly to analyze and summarize the sales data, fill in and update the various software data. To visit retail customer occupies most of the customer's work content, so how to optimize the business process of the customer manager's visiting customer in order to improve work efficiency and provide 
excellent service to the customer has important significance.
To visit the retail customer is mainly daily work to the account manager; the chart of the business process is as following.

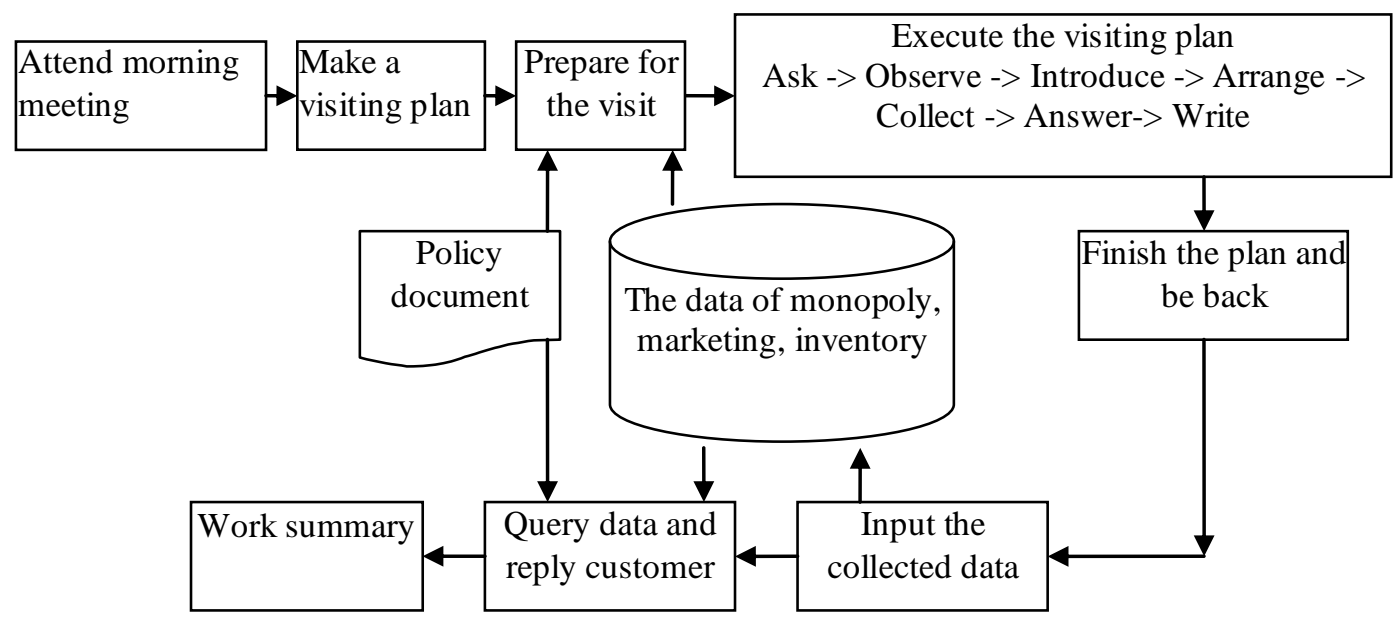

Figure 1. Traditional business process of the customer manager in tobacco industry

\section{A. Attend the Morning Meeting}

Market department chief conveys the marketing policy, layouts the work focus.

\section{B. Make a Visiting Plan}

According to the visiting frequency of customer and the visiting tasks, the customer manager carefully fills out the visit schedule.

\section{Prepare for the Visit}

The manager should prepare and print the information including the visiting plan, the distribution of goods, product introduction, Introduction of price tags, promotion plan, etc. and should prepare auxiliary tools including pen, record, rags, etc. and other personal items.

\section{Implementation of the Visiting Plan}

The account manager starts the visiting trip accordance with the client's list of the visit plan and provides seven services to each customer: sales.

Ask: to greet and ask about the information of recent

Observe: Observe whether the stock is reasonable; whether the cigarette display is neat; whether the price tag is complete and so on.

Introduce: introduce the marketing policies, the brand change, and the supply of goods and recommend the new brand and so on.

Arrange: help to arrange the counter, the cigarette and the price tag.

Collect: collect the market information, the retail customer information, the feedback information from the retail customer.

Answer: answer the question that the customer asked.

Write: write down all the collected information.

\section{E. Finish the Plan and Be Back}

\section{F. Input and Submit}

Input and submit the collected information to the corresponding management information systems.

\section{G. Query Data and Reply Them to the Customer}

Query the information from the management information systems and give a clear reply to the retail customer.

\section{H. Work Summary}

Summarize a brief report about the day's visit and submit it to the chief.

\section{PROBLEMS IN THE BUSINESS PROCESS OF THE CUSTOMER MANAGER}

The main problems of the business process of the customer manager in tobacco industry

\section{A. information processing is not timely}

In the traditional way, once the customer manager goes to visit the customers, they could not query the needed information or submit the corresponding information. He needs to return back to the office and then he can query, fill in and update the needed information in the corresponding information systems.

\section{B. redundant information processing}

Before the visit, the customer manager needs to query and print a variety of information, in order to answer the customer's questions, introduce the products and recommend the new brand to the customer; in the visiting process, if the manager cannot answer the questions, he can only deal with it until he goes back to the office; for the collected information about the customers and from the customers, the manager needs to write them down in the notebooks, and he can only fill in and submit the collected information to the corresponding systems when he is back in the office. Multiple query information and record information might cause a low efficiency. 


\section{C. lack of trace information on the work of the customer manager}

The lack of trace information on the work of the customer manager increases the difficulty of performance appraisal management to the customer manager. The performance appraisal to the manager relies on the visiting plan and the visiting report submitted by the customer manager. There is not an effective supervision mechanism to the visit.

\section{Business PROCESS Optimization OF THE \\ CUSTOMER MANAGER BASED ON MOBILE INTERNET}

The traditional information operation can only be carried out in fixed time, fixed location, fixed equipment and fixed network environment. Based on the mobile Internet technology, it can be changed to the mobile office model with portable mobile terminal equipment and can be deal with anywhere and anytime. With mobile Internet technology, the manager can do customer management, customer visit, order tracking, information query, information retrieval, information updating, information feedback, brand building, customer service and so on when he is visiting a customer. He can help the customer to analyze the business management and the brand composition of the customer and provide Business advisory services to the customer one-to-one. It is possible to realize service process information and promote customer service level to further improve.

When the customer manager visits a customer, he can sign in and sign out by using the mobile terminal. Based on 3G mobile wireless network and GIS/GPS, the visited trajectory of the customer manager is recorded and is provided as trace information for performance appraisal management to the manager.

Based on mobile Internet technology, optimize the business process of the customer manager, as shown in the following figure.

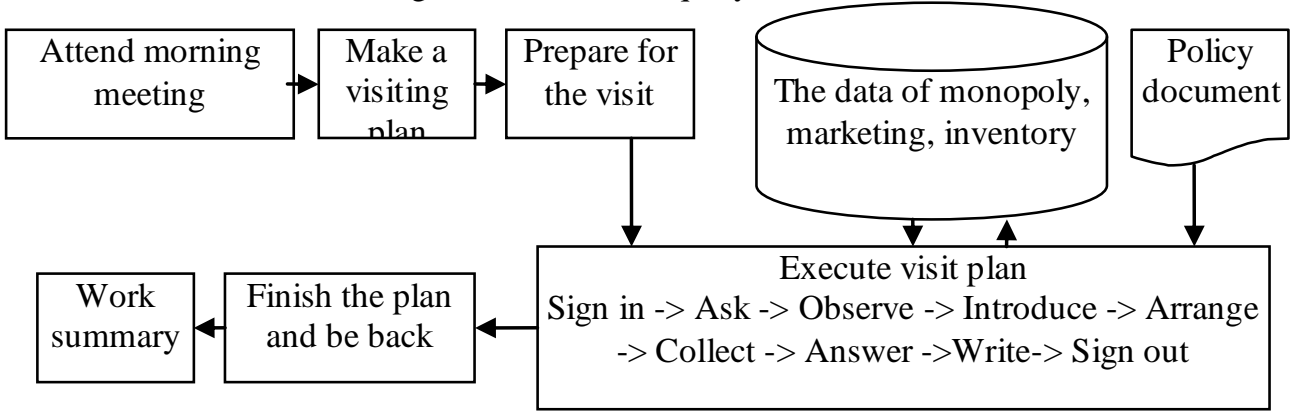

Figure 2. Optimized business process of the customer manager in tobacco industry

After the optimization of the customer manager business process, the two steps "Input the collected data" and "Query data and reply customer" are eliminated and the part of the tasks is merged into the step "Execute the visiting plan". Based on the mobile terminal office platform, the customer manager can change the previous work pattern which the manager must print out the plan and carry a notebook to write down the collected information and cannot fill in the information until he return back to the marketing department to the new work mode which the manager can query visiting plan and other needed information and reply the question anytime and anywhere. To the changed information of the customer or other collected information, the manager can fill in and update the information to the corresponding management information system on time. It can avoid the multiple processing of information, reduce the chance of input error and improve the work efficiency.

Customer manager is also through the mobile terminal of electronic sign and logout and to realize the real-time collection client manager work position and time information enhance the personnel management of pertinence and accuracy. Using GPS positioning and navigation functions, customer visits the customer's path to optimize and navigation services, shortens the time of customer manager, and improves the work efficiency.

\section{CONCLUSION}

The goal of business process optimization is to increase the service time and efficiency of the value-added service, shorten or remove the service time of non value-added service; Business process optimization cannot be separated from the support of information technology. The paper analyzes the traditional business process of customer manager in tobacco industry, points out its faults and existing problems, and then optimizes the traditional business process of the customer manager based on mobile Internet technology, eliminates the redundant business process. Through practice, the optimized business process can improve the efficiency of customer manager and provide better service to the customer.

\section{ACKNOWLEDGMENT}

This work is supported by National Natural Science Foundation of China (No.61272431), Humanity and Social Science foundation of Education Ministry of China (No. 14YJC860011), Shan Dong Province Natural Science Foundation of China (ZR2011FL020), Science and technology project of Shandong Tobacco Monopoly Bureau (Research on lean marketing management system of Shandong tobacco based on mobile Internet, No.KR224).

\section{REFERENCES}

[1] Shui Cangxi, The Internet Era @ Business Process Re-engineering, China Economic Publishing House, 2015.4, p128

[2] Li Chuanbo, Yang Songhui, "Post logistics business process optimization based on the RFID technology", Management and Technology Communications, February 2013, p20-24 
[3] Wang Qingyun, "Business process optimization of University Library under the information environment", JOURNAL OF XINGTAI UNIVERSITY, Vol. 27, No. 2, Jun. 2012 p148-149

[4] Chu Yuelong, "Optimization principle and implementation path of enterprise business process based on Information Technology", Commercial Era, 2013.25, p100-101

[5] Zhang Jian, Luo Hongmei, Yi Wenyan, "Optimization of business process and the "three flow" of B2C e-commerce based on Internet of things-In Wuhan Zhongbai storage case", Technology Outlook, 2014.13, p188-189

[6] ZhaoXi, "Business process optimization based a cloud computing architecture", MICROELECTRONICS\&COMPUTER, Vol.30, No.3, March 2013, p160-164
[7] Huang Meng and Shu Boyang, "Tourism Supply Chain challenges and transformation based on Mobile Internet Environment". Modern business trade industry, 2015, p52-54

[8] Zhao Hui, "Research on cigarette marketing innovation based on mobile Internet technology", Management Observer, June 2015, p180-181,

[9] Jia Yanbo. "Analysis and design of tobacco monopoly management supervision system based on mobile Internet technology", Beijing University of Posts and Telecommunications, 2012.6

[10] Lv Feng, "Integration and application of tobacco monopolization management system based on mobile internet", Nanjing University of Posts and Telecommunications,2014.3 